\title{
Discovery of ZACA reaction : Zr-catalyzed asymmetric carboalumination of alkenes
}

\author{
Ei-ichi Negishi \\ Herbert C. Brown Laboratories of Chemistry, Purdue University, \\ 560 Oval Drive, West Lafayette, Indiana 47907-2084, USA \\ E-mail: negishi@purdue.edu
}

\author{
This paper is dedicated to Professor U. M. Dzhemilev in recognition \\ and appreciation of his pioneering contributions to organometallic chemistry
}

\begin{abstract}
A single-stage, i.e., degree of polymerization of one, and enantioselective version of the ZieglerNatta alkene polymerization was envisioned as a potentially significant and useful method for catalytic asymmetric $\mathrm{C}-\mathrm{C}$ bond formation, shortly after the corresponding alkyne version involving Zr-catalyzed alkylalumination of alkynes was discovered in 1978. However, the discovery of such an asymmetric reaction proved to be a major challenge. At least three widely observable unwanted side reactions, i.e., (1) cyclic carbometalation, (2) $\beta$-H transfer hydrometalation, and (3) alkene polymerization, represented by the Ziegler-Natta polymerization, were noted and were to be avoided. With $\mathrm{Zr}$ as the metal at the catalytic center, we eventually came up with a notion that di- or multiple alkylation of $\mathrm{Zr}$ was to be avoided for achieving superior acyclic asymmetric carbometalation. This, in turn, led us to avoid the use of highly nucleophilic alkylmetals containing alkali metals and $\mathrm{Mg}$. Aluminum used in ZieglerNatta polymerization that can selectively monoalkylate $\mathrm{Zr}$ proved to be one of a very limited number of favorable metals. Even so, undesirable cyclic carbozirconation can occur in nonpolar solvents via intricate bimetallic routes to cyclic organozirconium species. The vastly different reactant-catalyst stoichiometry and the absence of polymerization promotors, such as methylaluminoxane, in our investigations permit us to ignore the Ziegler-Natta polymerization as a serious and unwanted side reaction, although use of limited amounts of promotors can in some cases accelerate otherwise sluggish ZACA reactions. Selection of the currently used Zr catalysts including $(R)$ - and $(S)-(\mathrm{NMI})_{2} \mathrm{ZrCl}_{2}$, dichlorobis(neomenthylindenyl)zirconium was made by screening 15 or so known chiral zirconocene derivatives. Systematic scientific design and screening of chiral ligands are clearly highly desirable, and efforts along this line are ongoing. Even at the current level of development, however, the ZACA reaction shows considerable promise as an efficient and selective method for catalytic asymmetric $\mathrm{C}-\mathrm{C}$ bond formation, which has already been used to significantly modernize and improve syntheses of natural products including deoxypolypropionates and isoprenoids of biological and medicinal interest.
\end{abstract}


Keywords: ZACA reaction (Zirconium-catalyzed Asymmetric Carboalumination of Alkenes), $(R)$ - and $(S)-(\mathrm{NMI})_{2} \mathrm{ZrCl}_{2}$ [dichlorobis(neomenthylindenyl)zirconium], ZACA-Pd-catalyzed vinylation tandem process, 2-chirally branched 1-alcohols, ZACA-Lipase-catalyzed acetylation synergy

\section{Table of Contents}

1. Introduction

1.1 Alkyne elementometalation as selective routes to alkenylmetals as well as alkenyl halides and other related alkenyl electrophiles

1.2 Historical and mechanistic background of carbometalation of alkenes and alkynes with alkylzirconocenes derivatives

1.3 Catalytic asymmetric carbometalation of alkenes proceeding via Dzhemilev ethylmagnesiation

2. Current Summary of Development and Application of ZACA Reaction and Conclusion

3. Acknowledgements

4. References and Notes

\section{Introduction}

Half a century ago, organic synthesis was performed mostly with organic reagents mainly consisting of $\mathrm{C}, \mathrm{H}, \mathrm{N}, \mathrm{O}, \mathrm{P}, \mathrm{S}$, and halogens supplemented with a few alkali metals and $\mathrm{Mg}$. Learning about the magical power of B providing all important Lewis-acidic centers from H. C. Brown's lectures in 1962 in Philadelphia and the "super" acidic power of the Al-Ti combination from a lecture in Tokyo in 1964 by K. Ziegler, who had just won a Nobel Prize, firmly set the direction of my life-long pursuit of new and useful organic synthetic methods through consideration of all usable elements in the Periodic Table, namely about 70 or so non-radioactive elements excluding inert gases and several inherently toxic elements, such as $\mathrm{Be}, \mathrm{As}, \mathrm{Cd}, \mathrm{Hg}, \mathrm{Pb}$, and perhaps also Sn and $\mathrm{Tl}$ and, as deemed desirable or even mandatory, their binary or even ternary combinations, persuasively exemplified by Ziegler's Al-Ti combination as one of several thousand available binary combinations. It should be understood that, fundamentally, electron deficiency most explicitly represented by metal-containing Lewis-acidic species rather than electron-rich nucleophilic species should serve as effective triggers for chemical reactions, although different but similarly powerful roles of radicals must never be forgotten. Equally important is full realization that any chemical species including all "coordinatively saturated" octet, 18-electron species, and so on can serve as potential Lewis acids as long as their LUMOs are or can be made sufficiently low-lying. 
With a very primitive and vague notion along the line of what is stated above in mind, I joined the research laboratories of the late Professor H. C. Brown as a Postdoctoral Associate in 1966 and later served as his Assistant (1968-1972). My journey with Lewis acidic B compounds began with investigations of carbonylation of organoboranes ${ }^{1}$ (Equations 1 and 2). As fascinating as this reaction was, it has never penetrated into the realm of organic synthesis, at least to date, even though hydroboration needed for the preparation of the requisite organoboranes is now a synthetic tool for every synthetic chemist. Perhaps, these highly unique modes of skeletal construction with organoborons would not readily be assimilated into the traditional synthetic arsenal.

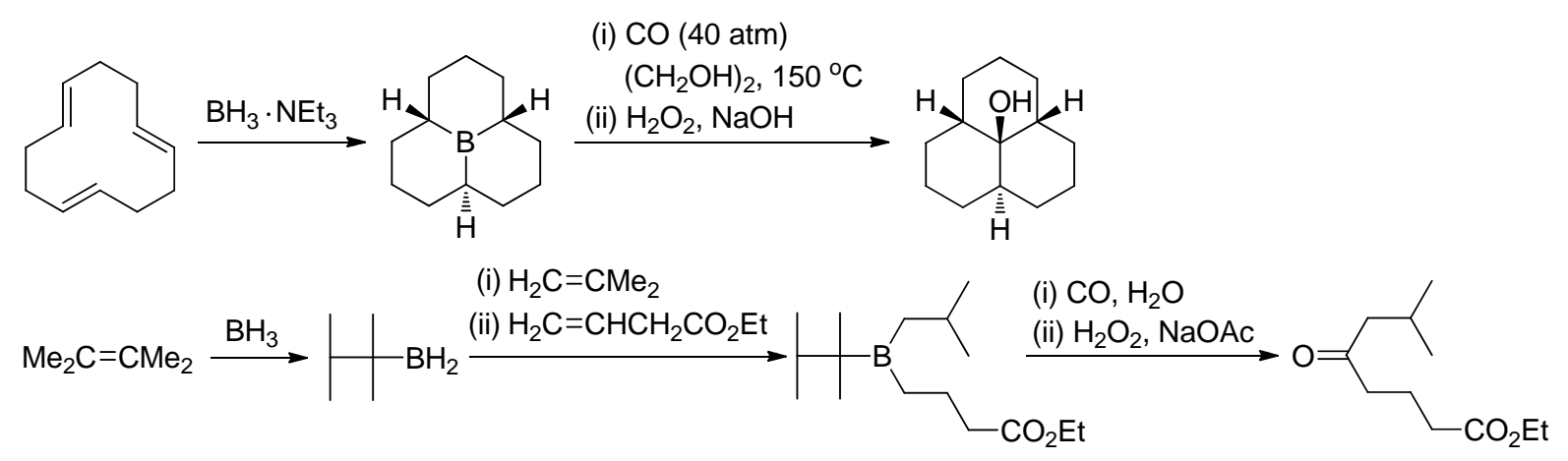

In search for a very widely applicable method for $\mathrm{C}-\mathrm{C}$ bond formation, cross-coupling (Equation 3) soon became my obsession without knowing how to do it. As of 1967, crosscoupling carried out with organolithiums and Grignard reagents without catalysts was of very limited scope, and cross-coupling as a whole was something to be avoided. It was about that time, however, the use of $\mathrm{Cu}$, mostly in stoichiometric amounts, for boosting the reactivity of organometals containing $\mathrm{Li}$ and $\mathrm{Mg}$ in conjunction with prostaglandin syntheses became actively pursued. Thus, combinations of main group metals, such as $\mathrm{Li}, \mathrm{Mg}$, and perhaps $\mathrm{B}$ and others, and $\mathrm{Cu}$ and possibly other transition metals became the main theme of my research proposals at Syracuse University, where I went as an Assistant Professor in 1972. All of our numerous attempts with $\mathrm{Li}, \mathrm{Mg}$, and $\mathrm{B}$ used in conjunction with $\mathrm{Cu}$ during the first few years miserably failed. Later, we found that $\mathrm{CuI}$ we obtained from our stockroom was old and impure. In the meantime, all of my research proposals were turned down mainly because all of my proposals dealt extensively with organoboranes, which I had extensively dealt with under H. C. Brown for several years. One critically important turning point then was our recognition of Tamao's Nicatalyzed Grignard cross-coupling ${ }^{2}$ brought to my attention by the late Dr. R. E. Merrill, a superb postdoctoral associate funded by Syracuse Chemistry Department Chairman, G. Vincow. Our quixotic attempts to catalyze cross-coupling of alkenylboranes with Ni was never successful, but the use of the corresponding alkenylalanes was highly successful. ${ }^{3}$ Our immediate screening of $\mathrm{Ni}, \mathrm{Pd}$, and Pt clearly revealed, for the first time, the generally optimal catalytic activities of Pd. ${ }^{3 b}$ Further systematic screening of metal countercations indicated the superior properties of 
$\mathrm{Zn}^{4}$ and $\mathrm{Zr}{ }^{4 \mathrm{~d}, 5}$ in addition to $\mathrm{Al}^{4}$ and $\mathrm{Mg}^{4 \mathrm{a}, 6}$ as well as $\mathrm{B},{ }^{7,8}$ and $\mathrm{Sn}^{7 \mathrm{a}, 9}$ With later additions by others including $\mathrm{Cu},{ }^{10} \mathrm{Si},{ }^{11} \mathrm{In},{ }^{12} \mathrm{Mn},{ }^{13}$ and so on, the Pd- or Ni-catalyzed cross-coupling has already become one of the most widely applicable, selective, and satisfactory methods for $\mathrm{C}-\mathrm{C}$ single bond formation. ${ }^{14}$

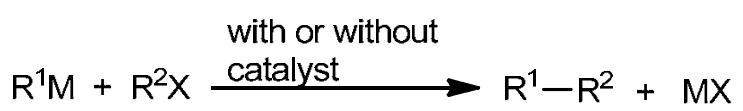

$\mathrm{R}^{1}, \mathrm{R}^{2}=$ aryl, alkenyl, alkynyl, benzyl, allyl, propargyl, alkyl, acyl, cyano, enoxy, etc.

M = Zn, Zr, Al (Negishi), B (Suzuki), Mg (Tamao), Sn (Stille), Si (Hiyama), Cu, In, Mn, etc.

$X=I, B r, C l, F$, OTs, OTf, etc.

catalyst $=\mathrm{PdL}_{n}, \mathrm{NiL}_{n}$, etc.

Without going into many details, the following generalizations may be profitably noted about the currently available cross-coupling methodology. (1) As long as the two starting compounds, i.e., $\mathrm{R}^{1} \mathrm{M}$ and $\mathrm{R}^{2} \mathrm{X}$, are preparable, the formation of $\mathrm{MX}$ through bond formation between the most electropositive group $\mathrm{M}$ and the most electronegative group $\mathrm{X}$ should make the overall process thermodynamically favorable barring some exceptions. (2) The remaining major task then is to make the desired process kinetically accessible and facile without undue intervention of unwanted side reactions. This is a much more difficult and serious problem to be controlled. Even so, combinations of superior Pd catalysts and metal counter-cations including $\mathrm{Zn}, \mathrm{Zr}, \mathrm{Al}$ (Negishi coupling), ${ }^{14} \mathrm{~B}$ (Suzuki coupling), ${ }^{15}$ and a few others, such as $\mathrm{Mg}, \mathrm{Cu}$, and In, have provided satisfactory cross-coupling procedures for the majority of all conceivable types of cross-coupling combinations. ${ }^{14 \mathrm{~b}, 14 \mathrm{c}}$ In many cases where the desired cross-coupling reactions are both thermodynamically and kinetically favorable, catalyst turnover numbers (TONs) reaching and exceeding a million $\left(10^{6}\right)$ and many approaching a billion $\left(10^{9}\right)$ and even higher have been observed, ${ }^{16}$ making not only the cost of operation but also alleged toxicity concerns attributed to Pd practically insignificant. Although not extensively investigated in our research group, brief comparisons of the allegedly "greener" ${ }^{1} \mathrm{H}$ reactions, such as Heck alkenylation, ${ }^{17}$ vs. Negishi and Suzuki versions of Pd-catalyzed alkenylation, predictably and clearly indicate that Heck alkenylation without a regio- and stereochemical tag $\mathrm{M}$ in $\mathrm{R}^{1} \mathrm{M}$ used in the corresponding $\mathrm{Pd}$ catalyzed cross-coupling is of significantly narrower applicability, lower selectivity leading to lower yields, and considerably lower TONs. ${ }^{17 \mathrm{c}-17 \mathrm{f}}$ In those cases where these issues are nonexistent or insignificant, selection of such $\mathrm{R}^{1} \mathrm{H}$ reactions may be well justified for their relative simplicity. In the other cases, however, thorough comparisons taking into consideration all pertinent factors must be made carefully. 


\subsection{Alkyne elementometalation as selective routes to alkenylmetals as well as alkenyl halides and other related alkenyl electrophiles}

As mentioned earlier, it does appear that the synthetic scope of the Pd-catalyzed cross-coupling is limited primarily by the availability of satisfactory routes to the requisite $R^{1} M$ and $R^{2} X$. From an optimistic viewpoint, one can state and expect that the synthetic scope of the Pd-catalyzed cross-coupling will continue to expand with discoveries and developments of new selective and satisfactory routes to $\mathrm{R}^{1} \mathrm{M}$ and $\mathrm{R}^{2} \mathrm{X}$ in the future. One of the major concerns in our own group from the beginning in the mid-1970s has been to be able to synthesize any conceivable types of alkenes, especially acyclic ones. To this end, our major efforts have been directed to the development of high-yielding as well as regio- and stereoselective alkyne hydrometalation especially with $\mathrm{B}, \mathrm{Al}$, and $\mathrm{Zr}$, etc., carbometalation with $\mathrm{Al}-\mathrm{Zr}$ combination, $\mathrm{Cu}$, etc., and haloboration. These elementometalation reactions have also been significantly supplemented by conventional alkyne polar addition reaction of high selectivity. Gratifyingly, highly ( $\geq 98 \%$ ) regio- and stereoselective features of alkene reagents thus prepared have indeed been retained in most cases of Pd-catalyzed Negishi alkenylation and also in an increasing number of cases of Suzuki alkenylation. As these alkyne elementometalation-Pd-catalyzed alkenylation tandem processes have been extensively discussed in our recent review, ${ }^{14 c}$ they will not be duplicated here, and the readers are referred to this review.

At the time we discovered the Zr-catalyzed carboalumination of alkynes in $1978,{ }^{18 a}$ a dreamy thought of expanding the scope of this reaction so as to embrace its alkene version for asymmetric $\mathrm{C}-\mathrm{C}$ bond formation, which would amount to the single-step version of the ZieglerNatta alkene polymerization captured my mind. However, this seemingly easy task proved to be quite challenging, and several intermittent attempts over seventeen years supported heavily by our ongoing systematic investigations of zirconocene chemistry were needed to finally discover in 1995 the Zirconium-catalyzed Asymmetric Carboalumination of Alkenes (ZACA reaction hereafter), ${ }^{19}$ as detailed below.

\subsection{Historical and mechanistic background of carbometalation of alkenes and alkynes with alkylzirconocenes derivatives}

The Zr-catalyzed methylalumination of alkynes (ZMA reaction) was shown to involve one-step syn-addition of a $\mathrm{Me}-\mathrm{Zr}$ bond to 1-alkynes in an anti-Markovnikov manner followed by $\mathrm{Zr}$-to-Al transmetalation on the resultant carbon group. ${ }^{18 \mathrm{~b}}$ This reaction involves acyclic carbometalation of a "super-acidic"18c,18d Zr-Al bimetallic system (Scheme 1). 

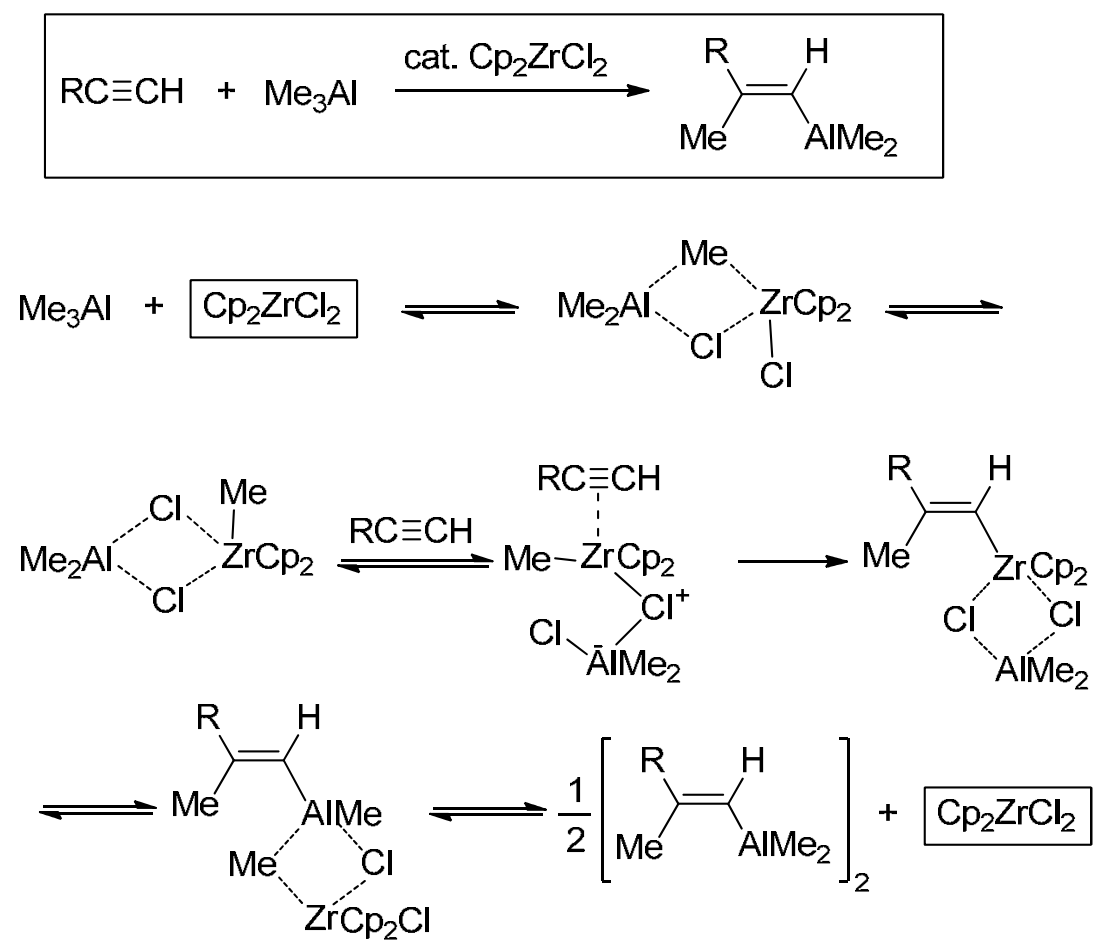

Scheme 1. Bimetallic acyclic carboalumination mechanism. ${ }^{18 \mathrm{~b}}$

Several years later, Dzhemilev reported a seemingly analogous reaction of Zr-catalyzed carbomagnesiation of alkenes with $\mathrm{EtMgBr}$ (Scheme 2). ${ }^{20}$ There did not appear any forcing reasons to suspect that the mechanisms of these two closely analogous reactions should be radically different. Through our systematic investigations of the " $\mathrm{ZrCp}_{2}{ }$ chemistry, ${ }^{21}$ however, we accidentally clarified that the Dzhemilev ethylmagnesiation of alkenes actually proceeded via a highly intricate series of transformations via (i) formation of $\mathrm{Et}_{2} \mathrm{ZrCp}_{2}$, (ii) $\beta$-agostic interaction-induced intramolecular "acid-base" interaction producing a zirconacyclopropane 1a which may also be viewed as a zirconocene-ethylene $\pi$-complex $\mathbf{1 b}$, (iii) cyclic carbozirconation of an alkene with 1 to give, typically a 3-substituted zirconacyclopentane 2, (iv) subsequent reaction of 2 with another molecule of EtMgBr leading to $\beta$-agostic interaction-induced "acidbase" interaction producing a 2-ethyl-1-alkylmagnesium bromide with regeneration of ethylene$\mathrm{ZrCp}_{2} \pi$-complex 1. All of the steps proposed above have been independently and amply supported (Scheme 2). ${ }^{21,22}$ 


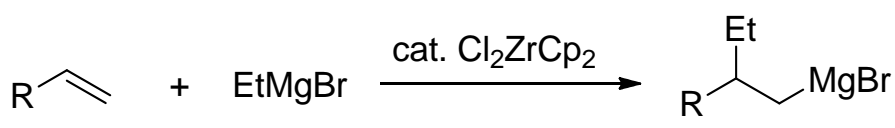

generation of the active catalyst (1)

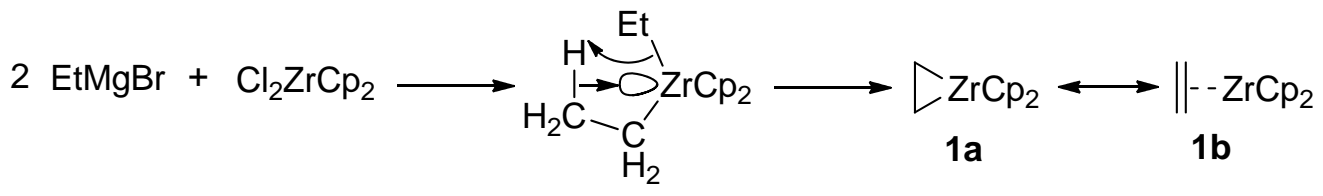

catalytic cycle

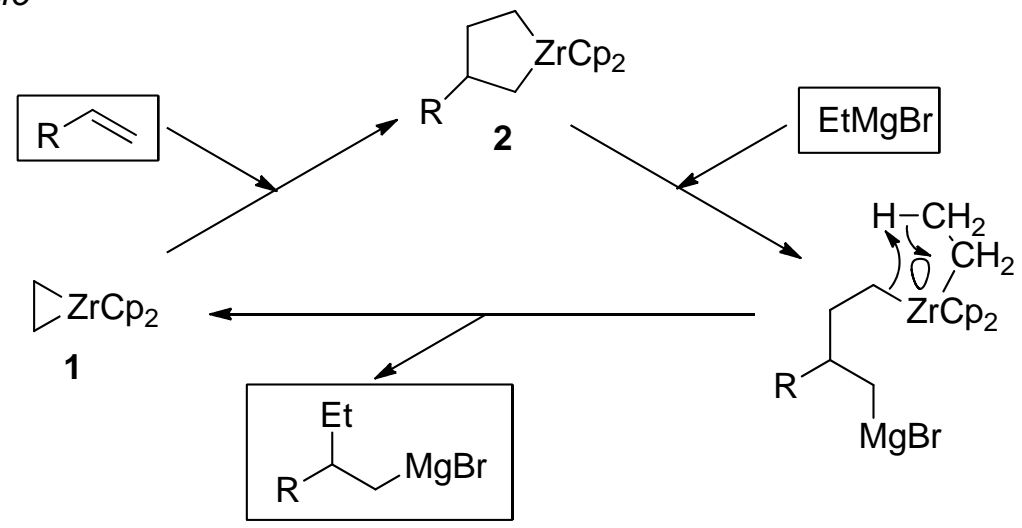

Scheme 2. Cyclic carbozirconation mechanism for the Dzhemilev ethylmagnesiation.

We believe that both the discovery of the Dzhemilev ethylmagnesiation and our mechanistic clarification $^{22}$ have not only clearly established the existence of both acyclic and cyclic carbozirconation processes but also alerted us to sharply and carefully distinguish some seemingly analogous carbometalation reactions of zirconocene derivatives. We were later further surprised by the existence of bimetallic (involving both $\mathrm{Zr}$ and $\mathrm{Al}$ ) cyclic carbozirconation of alkynes and alkenes that may be viewed as a hybrid of acyclic and cyclic carbozirconation ${ }^{23}$ (Scheme 3). We also noted that our bimetallic ( $\mathrm{Zr}-\mathrm{Al}$ ) cyclic carbozirconation process closely resembled the corresponding carbotitanation of alkenes with titanium-carbene species that can be viewed as a two-membered titanacycle (Tebbe reagent) generated from a Ti-Al bimetallic system. ${ }^{24}$ Without going into detailed mechanistic discussions, the following brief summary may be presented: (i) Formation of metallacycles including metal-carbene complexes (two-membered metallacycles) is a widely observable phenomenon with coordinatively unsaturated organotransition metal complexes, especially in those cases where coordinatively unsaturated dialkylated organotransition metal species that are readily prone to $\beta$ - or even $\alpha$-agostic interaction-induced cyclization are generated. ${ }^{25}$ (ii) The propensity for generating the requisite "coordinatively unsaturated dialkyltransition metal species" rests on a delicate balance between the alkylating power of alkylmetal reagents, e.g., $\mathrm{RLi}>\mathrm{RMgX}>\mathrm{RAlX}_{2}---$, and their ability to avoid formation of coordinatively saturated "ate" complexes. Thus, for example, trialkylalanes, e.g., $\mathrm{Et}_{3} \mathrm{Al}$, do not dialkylate $\mathrm{ZrCp}_{2} \mathrm{Cl}_{2}$ to give $\mathrm{Et}_{2} \mathrm{ZrCp}_{2}$. On the other hand, Grignard reagents, e.g., EtMgBr, readily dialkylate to give a $16 \mathrm{e}^{-} \mathrm{Et}_{2} \mathrm{ZrCp}_{2}$. Triethylation does proceed, but it is 
readily reversible. All these make alkylmagnesium derivatives some of the optimal reagents for converting $\mathrm{ZrCp}_{2} \mathrm{Cl}_{2}$ into zirconacycles. (iii) Even with alkylalanes, however, zirconacycles may still be formed via "bimetallic intramolecular acid-base interaction" discussed above.

Overall equation

${ }^{n} \mathrm{Bu}={ }^{n} \mathrm{Bu}+2 \mathrm{Et}_{3} \mathrm{Al} \longrightarrow{ }_{\mathrm{AlEt}}^{{ }^{n} \mathrm{Bu}}+\mathrm{EtH}$

Catalyst generation and catalytic cycle

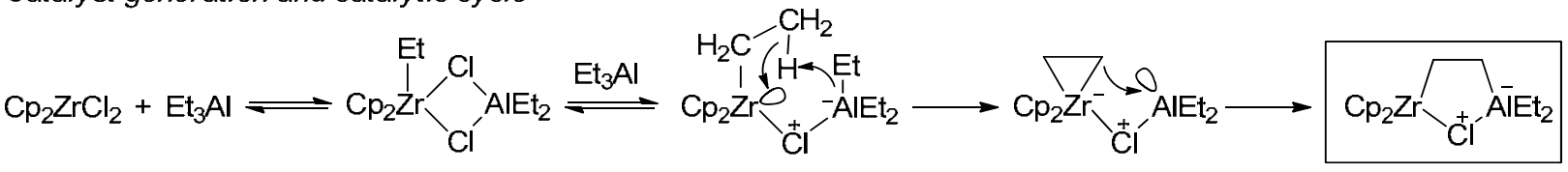

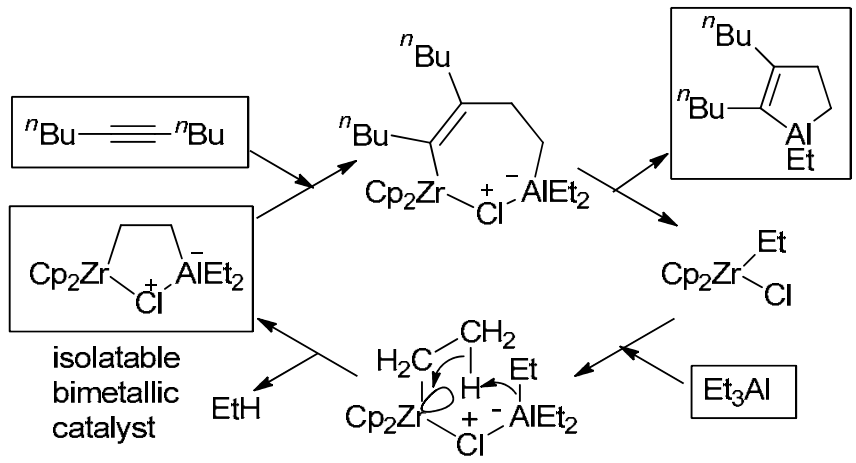

Scheme 3. Bimetallic cyclic carboalumination mechanism. ${ }^{23}$

\subsection{Catalytic asymmetric carbometalation of alkenes proceeding via Dzhemilev ethylmagnesiation}

The first catalytic and highly enantioselective alkene carbometalation with zirconocene derivatives was reportd by Hoveyda in $1993 .{ }^{26}$ Highly satisfactory results have been obtained through the use of Dzhemilev ethylmagnesiation of allyl ethers and allylamines (Scheme 4). Similar developments were also made later. ${ }^{27}$

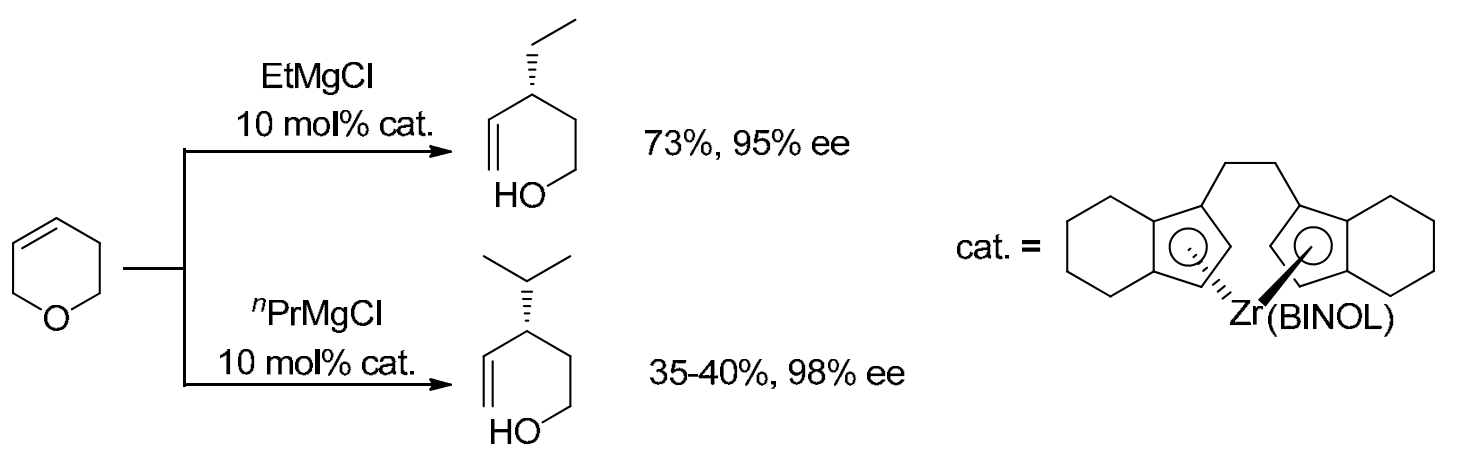

Scheme 4. Catalytic asymmetric carbometalation-elimination of allyl ethers with ethylmagnesium and chiral zirconocene derivatives. 
Although the enantioselectivity in some cases are spectacularly high, a few critical limitations should be noted. As might be expected from mechanistic details of Dzhemilev carbomagnesiation discussed above, introduction of the singularly important Me group is not readily feasible. While introduction of Et is satisfactory, that of $n \operatorname{Pr}$ and longer alkyl groups is accompanied by regioisomerization leading to the formation of unattractive product mixtures. $^{26-28}$ Clearly, new alternate reactions not requiring zirconacycles were needed, especially for the most highly desirable case of enantioselective methylmetalation. In the meantime, our own efforts toward this goal were miserably failing. We then noted that all of our very tentative feasibility investigations leading to negative results were conducted with the parent $\mathrm{ZrCp}_{2} \mathrm{Cl}_{2}$. We finally decided to commit ourselves to the following two studies: (1) detailed fact-finding investigation of the reaction of 1-decene with $10 \mathrm{~mol} \%$ of $\mathrm{ZrCp}_{2} \mathrm{Cl}_{2}$ in $\mathrm{CH}_{2} \mathrm{Cl}_{2}$ and (2) search for satisfactory procedures based on (1). These studies immediately led to some most useful results shown in Scheme 5. With $\left(\mathrm{Me}_{5} \mathrm{C}_{5}\right)_{2} \mathrm{ZrCl}_{2}$, no reaction was observed under the same conditions. ${ }^{19}$ Clearly, zirconocene derivatives of sufficiently, but not excessively, bulky ligands to suppress unwanted side reactions, most notably $\beta-\mathrm{H}$ transfer hydrometalation, while promoting the desired carbometalation, were needed for realizing our goal.
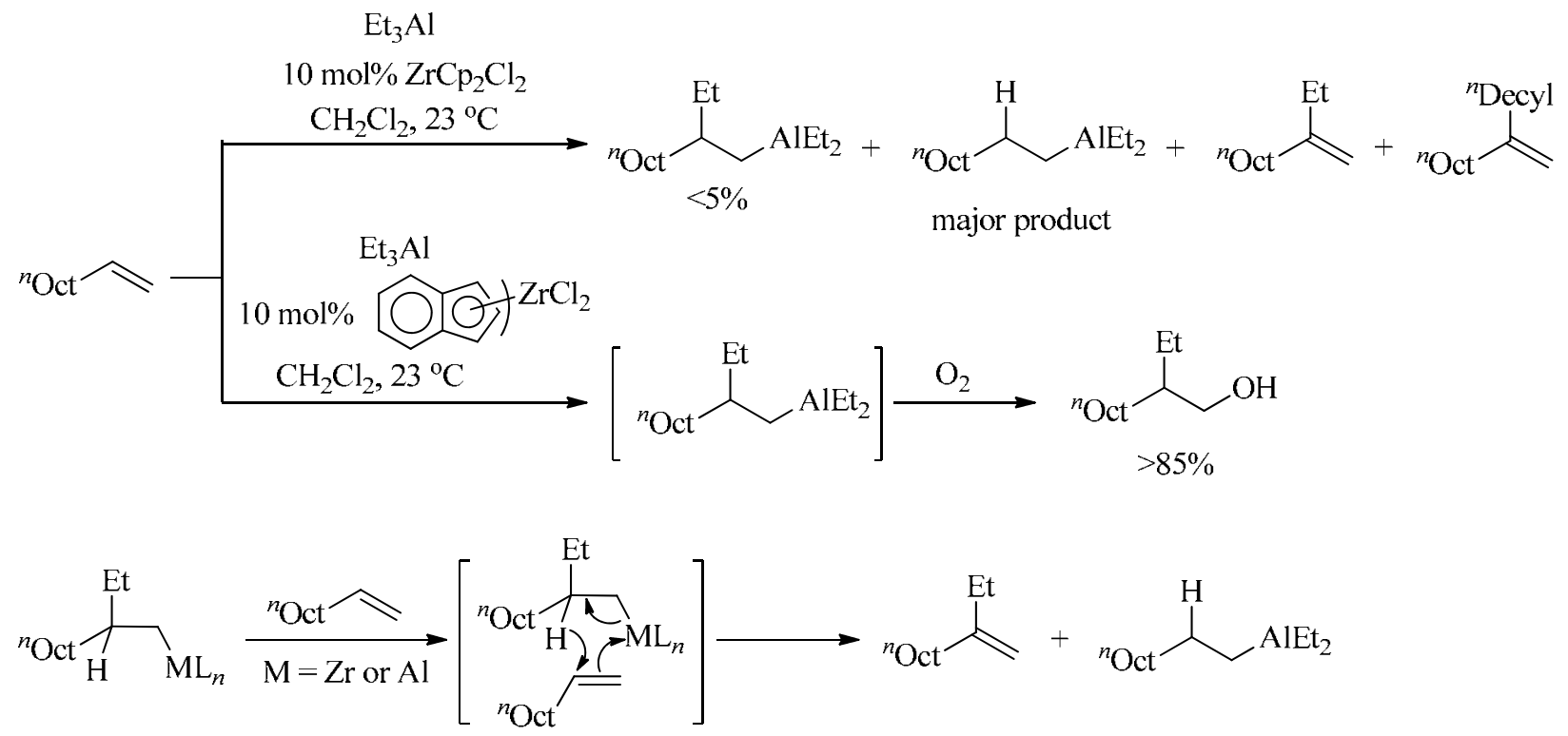

Scheme 5. Reaction of 1-decene with $\mathrm{Et}_{3} \mathrm{Al}$ in the presence of various zirconocene derivatives.

Yet another ambush we briefly encountered was the initially unexpected Al-Zr bimetallic cyclic carbometalation of alkenes. Before 1995, we believed that dialkylation of zirconocene derivatives would be mandatory for observing the formation of zirconacyclopropanes via $\beta$ agostic interaction-induced cyclization. We were, however, surprised to find out that the reaction of 1-decene with $\mathrm{Et}_{3} \mathrm{Al}$ in the presence of $(\mathrm{NMI})_{2} \mathrm{ZrCl}_{2}{ }^{29 \mathrm{a}} 3$ in hexanes would proceed by cyclic carbometalation $^{19 \mathrm{~b}}$ (Scheme 6), even though there were ample indications that trialkylalanes do 
not lead to dialkylation of zirconocene derivatives. It was indeed this surprising finding that led to the clarification and establishment of the bimetallic cyclic mechanism for carbozirconation of alkynes mentioned earlier (Scheme 3). ${ }^{23}$ Fortunately, we soon learned that the use of more polar solvents including $\mathrm{CH}_{2} \mathrm{Cl}_{2}, \mathrm{CH}_{3} \mathrm{CHCl}_{2}$, and $\left(\mathrm{CH}_{2} \mathrm{Cl}\right)_{2}$ almost totally suppressed the undesired cyclic carbometalation process thereby promoting formation of the desired products (Scheme 6). ${ }^{19}$

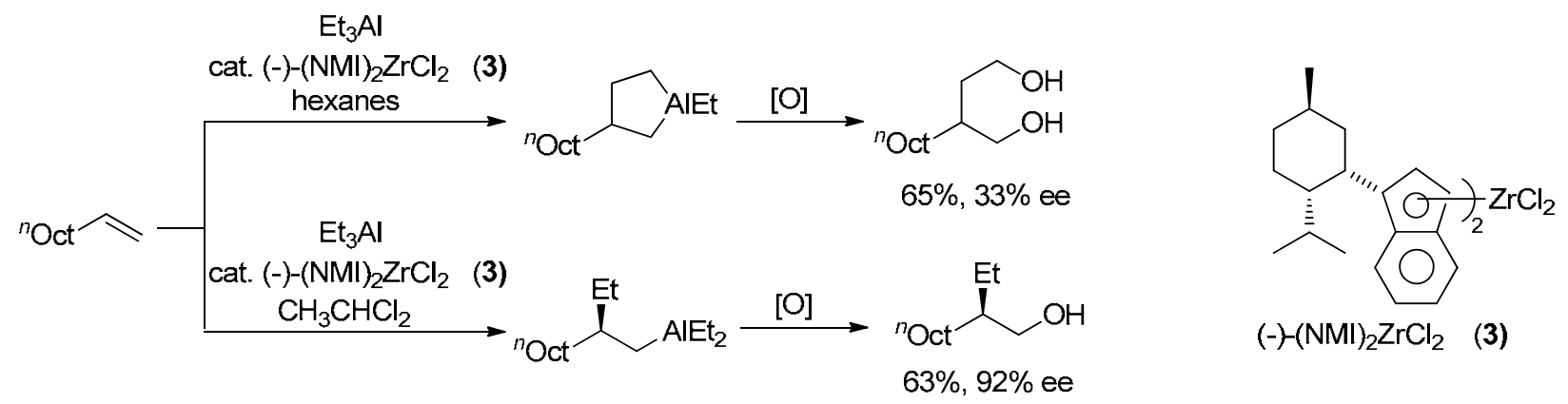

Scheme 6. Marked solvent effect in the reaction of 1-decene with $\mathrm{Et}_{3} \mathrm{Al}$ in the presence of $(\mathrm{NMI})_{2} \mathrm{ZrCl}_{2}$ (3).

Throughout our investigations, we were very much concerned about the third potential side reaction, i.e., Zr-catalyzed alkene polymerization of Ziegler and Natta. ${ }^{30}$ However, this has hardly been of any serious concern. In retrospect, this is not surprising, if one considers (i) essentially 1:1 alkene-to-alane ratios and (ii) absence of highly efficient polymerization promotors, such as methylaluminoxane (MAO), typically required in large quantities relative to trialkylalanes. In our ZACA reaction, the use of MAO and other promoters is not mandatory and typically not necessary, although addition of one equivalent or less of water or the corresponding amount of performed MAO can significantly promote otherwise slow ZACA reaction, ${ }^{31}$ such as that of styrenes.

Having learned about three major pitfalls, namely (1) cyclic carbometalation, (2) H-transfer hydrometalation, and (3) Ziegler-Natta-type alkene polymerization as well as how to avoid them, our remaining major task was to find some satisfactory chiral zirconocene catalysts. In this respect, we have not yet made a systematic catalyst optimization involving catalyst designing. Instead, we have merely screened a dozen to fifteen known chiral zirconocene complexes. In our cases, widely used (ebi) $\mathrm{ZrCl}_{2}{ }^{29 \mathrm{~b}}$ and its partially hydrogenated derivatives ${ }^{29 \mathrm{c}}$ were less effective. The most effective among those tested thus far is Erker's $(\mathrm{NMI})_{2} \mathrm{ZrCl}_{2}{ }^{29 \mathrm{a}}$ With either $(R)$ - or $(S)$ isomer of commercially available $(\mathrm{NMI})_{2} \mathrm{ZrCl}_{2}$, ${ }^{29 \mathrm{~d}}$ the approximate ranges of enantiomeric excesses observed in three mutually complementary ZACA reactions shown in Scheme 7 are 7095\% ee and the product yields are generally satisfactory, although there clearly exists room for improvement (Scheme 7). 


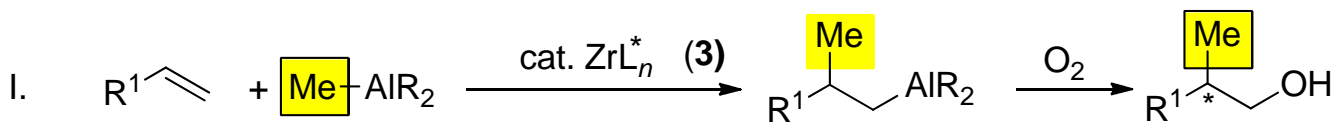
Yields: good to excellent ee: $70-90 \%$

II. $\mathrm{R}^{1}-\mathrm{AlR}_{2}+\stackrel{\mathrm{Me}}{\text { cat. } \mathrm{ZrL}_{n}^{*} \text { (3) }} \underset{\mathrm{R}^{1}}{\mathrm{Me}} \mathrm{AlR}_{2} \stackrel{\mathrm{O}_{2}}{\longrightarrow} \underset{\mathrm{R}^{1}}{\stackrel{\mathrm{Me}}{\star} \mathrm{OH}}$ Yields: modest to good (need improvement) ee: $85-95 \%$

III.

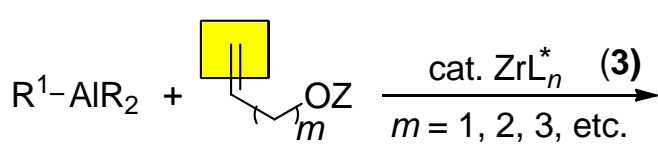<smiles>[R20]CC([R])C[OH+]</smiles>

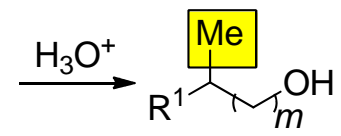

Yields: good to excellent ee: $90-95 \%$

Scheme 7. Three protocols for enantioselective synthesis of methyl-substituted 1-alkanols.

\section{Current Summary of Development and Application of ZACA Reaction and Conclusion}

Although no detailed discussion of applications of the ZACA reaction is intended here, the following favorable features of this novel asymmetric $\mathrm{C}-\mathrm{C}$ bond formation reaction may be noted and exploited. In the interest of providing a full list of the publications on ZACA reaction by the author's group, all original papers and pertinent reviews and so on are listed as references. ${ }^{18 \mathrm{~d}, 19,21,32-56}$

(1) ZACA reaction is a novel and rare catalytic asymmetric $\mathrm{C}-\mathrm{C}$ bond formation reaction of terminal alkenes of one-point-binding without requiring any other functional groups, even though various functional groups may be present.

(2) There are a few or possibly more alternate and mutually complementary procedures to choose from, allowing highly flexible designs for the syntheses of chiral organic compounds ${ }^{33,35}$ (Scheme 7).

(3) In cases where the ZACA products are obtained as 2-chirally branched 1-alcohols via simple oxidation, typically with $\mathrm{O}_{2}$, of alanes, lipase-catalyzed acetylation-ordinary column chromatography provides a widely applicable and convenient method of purification by taking advantage of the sufficiently high ZACA-generated 70-95\% enantiomeric excess levels of the crude products. $^{41}$

(4) In more demanding cases, proximally ( $\gamma$ - or $\delta$-) heterofunctional and hence readily purifiable 2-chiral 1-alcohols may be prepared first, purified, and further converted. ${ }^{57}$ 
(5) In the syntheses of compounds with two or more chiral centers, the principle of statistical enantiomeric amplification is operative. For the syntheses of deoxypolypropionates, for example, homologation by one 1,2-propylidene unit can be performed in one pot via ZACA-Pd-catalyzed vinylation tandem process. ${ }^{38}$ At a realistic average enantioselectivity level of $80 \%$ ee, di-, tri- and tetrameric deoxypolypropionates are reliably predicted to be ca. 98, 99.9, and 99.99\% ee, respectively. ${ }^{34,35}$ The only remaining task for preparing ultra-pure deoxypolypropionates is ordinary and very facile chromatographic purification of newly formed 2,4-dimethyl-1hydroxybutyl moiety one at a time. ${ }^{34-36,38,39}$

We believe that the ZACA reaction is a widely applicable, high-yielding, efficient and selective method for asymmetric $\mathrm{C}-\mathrm{C}$ bond formation that is potentially economical. As of today, however, it has not yet been widely embraced by the organic synthetic community, although its application to natural products synthesis by other workers is known. ${ }^{31}$ In the meantime, our own efforts to apply it to catalytic asymmetric syntheses of chiral natural products have been very enjoyable and most rewarding. In this review, only the names and structures of natural products and related compounds including about a dozen that have been totally synthesized through the use of ZACA reaction are presented in Table 1. It is indeed gratifying to note that the ZACA-Pd- or Cu-catalyzed cross-coupling synergy does provide, in most cases, substantial improvements in efficiency and selectivity leading to significant increases in overall yields of pure desired compounds over the previous syntheses of the same or related compounds. Coupled with various flexible options for purifying optically active products to ultra-high (>>99\%) purity levels, its wide-spread application in the near future may be anticipated.

\section{Acknowledgements}

The author thanks all of those who have contributed to our ZACA project and are cited in our publications. Following promising leads provided by a number of earlier coworkers, notably D. E. Van Horn and T. Takahashi, the ZACA reaction was almost single-handedly discovered by D. Y. Kondakov and significantly further developed by S. Huo. Its more recent development to the current level was mainly performed by a trio of Z. Tan, T. Novak, and B. Liang as well as by more recent members including G. Zhu, Z. Huang, and the current trio of G. Wang, C. T. Lee, and $\mathrm{S}$. $\mathrm{Xu}$. We have greatly benefited from contributions by other workers, especially G. Erker and P. Wipf.

Over the years our investigation in this area has been supported by NSF, NIH, Purdue University, Albemarle, Boulder Scientific Co., Johnson-Matthey, Wako Chemical, and, last but not least, Aldrich Chemical Co. 
Table 1. Natural products and related compounds of biological and medicinal interest synthesized via ZACA reaction by the Authors' group

\begin{tabular}{|c|c|c|c|}
\hline Entry & $\begin{array}{c}\text { Chiral } \\
\text { compounds of } \\
\text { biological and } \\
\text { medicinal } \\
\text { interest (year) }\end{array}$ & Structure & $\begin{array}{l}\text { Total or } \\
\text { fragment } \\
\text { synthesis }\end{array}$ \\
\hline (1) & $\begin{array}{l}\text { vitamin } E(2001 \\
\text { and } 2002)^{32,33}\end{array}$ & & $\begin{array}{c}\text { total } \\
\text { synthesis }\end{array}$ \\
\hline (2) & $\begin{array}{l}\text { vitamin } K \\
(2001)^{32,41}\end{array}$ & & $\begin{array}{c}\text { total } \\
\text { synthesis }\end{array}$ \\
\hline (3) & phytol $(2001)^{32}$ & & $\begin{array}{c}\text { total } \\
\text { synthesis }\end{array}$ \\
\hline (4) & $\begin{array}{l}\text { scyphostatin } \\
(2004 \text { and } \\
2010)^{34,48}\end{array}$ & & $\begin{array}{l}\text { sidechain }^{34} \\
\text { and total } \\
\text { synthesis }\end{array}$ \\
\hline (5) & $\begin{array}{c}\text { TMC-151A-F } \\
\text { C11-C20 } \\
\text { fragment } \\
(2004)^{35}\end{array}$ & $\begin{array}{l}{ }^{6} \mathrm{H}_{8}(\mathrm{OH})_{5} \\
\text { or Ac }\end{array}$ & $\begin{array}{l}\text { C11-C20 } \\
\text { fragment }\end{array}$ \\
\hline (6) & $\begin{array}{l}\text { siphonarienal } \\
\qquad(2004)^{36}\end{array}$ & & $\begin{array}{c}\text { total } \\
\text { synthesis }\end{array}$ \\
\hline (7) & $\begin{array}{l}\text { siphonarienone } \\
\qquad(2004)^{36}\end{array}$ & & $\begin{array}{c}\text { total } \\
\text { synthesis }\end{array}$ \\
\hline (8) & $\begin{array}{l}\text { siphonarienolone } \\
(2004)^{36}\end{array}$ & & $\begin{array}{c}\text { total } \\
\text { synthesis }\end{array}$ \\
\hline (9) & $\begin{array}{c}(+) \text {-sambutoxcin } \\
\text { C9-C18 fragment } \\
(2004)^{36}\end{array}$ & & $\begin{array}{l}\text { C9-C18 } \\
\text { fragment }\end{array}$ \\
\hline
\end{tabular}


Table 1. Continued

\begin{tabular}{|c|c|c|c|}
\hline Entry & $\begin{array}{c}\text { Chiral } \\
\text { compounds of } \\
\text { biological and } \\
\text { medicinal } \\
\text { interest (year) }^{\text {ref }}\end{array}$ & Structure & $\begin{array}{l}\text { Total or } \\
\text { fragment } \\
\text { synthesis }\end{array}$ \\
\hline$(10)$ & $\begin{array}{c}\text { 6,7- } \\
\text { dehydrostipiamide } \\
(2004)^{37}\end{array}$ & & $\begin{array}{c}\text { total } \\
\text { synthesis }\end{array}$ \\
\hline$(11)$ & $\begin{array}{c}\text { ionomycin } \\
\text { C1-C10 fragment } \\
(2005)^{38}\end{array}$ & & $\begin{array}{l}\mathrm{C} 1-\mathrm{C} 10 \\
\text { fragment }\end{array}$ \\
\hline$(12)$ & $\begin{array}{c}\text { borrelidin } \\
\text { C3-C11 fragment } \\
(2005)^{38}\end{array}$ & & $\begin{array}{l}\text { C3-C11 } \\
\text { fragment }\end{array}$ \\
\hline (13) & $\begin{array}{l}\text { preen gland wax } \\
\text { of the graylag } \\
\text { groose, Anser } \\
\text { anser }(2006)^{39}\end{array}$ & & $\begin{array}{c}\text { total } \\
\text { synthesis }\end{array}$ \\
\hline$(14)$ & $\begin{array}{c}\text { doliculide } \\
\text { C1-C9 fragment } \\
(2006)^{39}\end{array}$ & & $\begin{array}{l}\text { C1-C9 } \\
\text { fragment }\end{array}$ \\
\hline$(15)$ & $\begin{array}{c}(+) \text {-stellattamide } \\
\text { A }(2007)^{41}\end{array}$ & & sidechain \\
\hline (16) & $\begin{array}{c}(+) \text {-stellattamide } \\
\text { B }(2007)^{41}\end{array}$ & & $\begin{array}{l}\text { C5-C11 } \\
\text { sidechain }\end{array}$ \\
\hline
\end{tabular}


Table 1. Continued

\begin{tabular}{|c|c|c|c|}
\hline Entry & $\begin{array}{c}\text { Chiral } \\
\text { compounds of } \\
\text { biological and } \\
\text { medicinal } \\
\text { interest (year) }^{\text {ref }}\end{array}$ & Structure & $\begin{array}{l}\text { Total or } \\
\text { fragment } \\
\text { synthesis }\end{array}$ \\
\hline$(17)$ & $\begin{array}{c}(-) \text {-spongidepsin } \\
(2007)^{42}\end{array}$ & & $\begin{array}{c}\text { total } \\
\text { synthesis }\end{array}$ \\
\hline$(18)$ & $\begin{array}{c}(+)- \\
\text { discodermolide } \\
(2007)^{43}\end{array}$ & & $\begin{array}{l}\text { C11-C17 } \\
\text { fragment }\end{array}$ \\
\hline (19) & $\begin{array}{c}(-) \text {-callystatin A } \\
(2007)^{43}\end{array}$ & & $\begin{array}{l}\text { C1-C11 } \\
\text { fragment }\end{array}$ \\
\hline$(20)$ & $\begin{array}{c}\text { archazolides A } \\
\text { and } B(2007)^{43} \\
A: R=M e \\
B: R=H\end{array}$ & & $\begin{array}{l}\text { C7-C15 } \\
\text { fragment }\end{array}$ \\
\hline$(21)$ & $\begin{array}{l}\text { nafyredin } \\
(2008)^{44}\end{array}$ & & $\begin{array}{l}\text { C9-C18 } \\
\text { fragment } \\
\text { (formal } \\
\text { total } \\
\text { synthesis) }\end{array}$ \\
\hline
\end{tabular}


Table 1. Continued

\begin{tabular}{|c|c|c|c|}
\hline Entry & $\begin{array}{c}\text { Chiral } \\
\text { compounds of } \\
\text { biological and } \\
\text { medicinal } \\
\text { interest (year) }^{\text {ref }}\end{array}$ & Structure & $\begin{array}{l}\text { Total or } \\
\text { fragment } \\
\text { synthesis }\end{array}$ \\
\hline (22) & $\begin{array}{l}\text { milbemycin } \beta_{3} \\
\qquad(2008)^{44}\end{array}$ & & $\begin{array}{l}\text { C1-C13 } \\
\text { fragment }\end{array}$ \\
\hline (23) & $\begin{array}{l}\text { bafilomycin } \mathrm{A}_{1} \\
\qquad(2008)^{44}\end{array}$ & & $\begin{array}{l}\text { C1-C11 } \\
\text { fragment }\end{array}$ \\
\hline (24) & $\begin{array}{l}\text { fluvirucinnin } A_{1} \\
\qquad(2008)^{45}\end{array}$ & & $\begin{array}{c}\text { total } \\
\text { synthesis }\end{array}$ \\
\hline$(25)$ & $\begin{array}{c}4,6,8,10,16,18- \\
\text { hexamethyldocos } \\
\text { ane }(2008)^{46}\end{array}$ & & $\begin{array}{c}\text { total } \\
\text { synthesis }\end{array}$ \\
\hline (26) & $\begin{array}{c}\text { yellow scale } \\
\text { pheromone } \\
(2008)^{47}\end{array}$ & & $\begin{array}{c}\text { total } \\
\text { synthesis }\end{array}$ \\
\hline
\end{tabular}

\section{References and Notes}

1. (a) Brown, H. C.; Negishi, E. J. Am. Chem. Soc. 1967, 89, 5477. (b) Brown, H. C.; Negishi, E. J. Am. Chem. Soc. 1967, 89, 5285.

2. Tamao, K.; Sumitani, K.; Kumada, M. J. Am. Chem. Soc. 1972, 94, 4374. 
3. (a) Negishi, E.; Baba, S. J. Chem. Soc., Chem. Commun. 1976, 596. (b) Baba, S.; Negishi, E. J. Am. Chem. Soc. 1976, 98, 6729. (c) Negishi, E.; Chatterjee, S.; Matsushita, H. Tetrahedron Lett. 1981, 22, 3737. (d) Matsushita, H.; Negishi, E. J. Chem. Soc., Chem. Commun. 1982, 160.

4. (a) Negishi, E.; King, A. O.; Okukado, N. J. Org. Chem. 1977, 42, 1821. (b) King, A. O.; Okukado, N.; Negishi, E. J. Chem. Soc., Chem. Commun. 1977, 683. (c) King. A. O.; Negishi, E.; Villani, F. J., Jr.; Silveira, A., Jr. J. Org. Chem. 1978, 43, 358. (d) Negishi, E.; Okukado, N.; King, A. O.; Van Horn, D. E.; Spiegel, B. I. J. Am. Chem. Soc. 1978, 100, 2254. (e) Negishi, E.; Valente, L. F.; Kobayashi, M. J. Am. Chem. Soc. 1980, 102, 3298. (f) Kobayashi, M.; Negishi, E. J. Org. Chem. 1980, 45, 5223. (g) Matsushita, H.; Negishi, E. J. Am. Chem. Soc. 1981, 103, 2882. (h) Negishi, E.; Matsushita, H.; Okukado, N. Tetrahedron Lett. 1981, 22, 2715. (i) Negishi, E.; Luo, F.-T.; Frisbee, R.; Matsushita, H. Heterocycles. 1982, 18, 117. (j) For an early contribution by other workers, see: Fauvarque, J. F.; Jutand, A. J. Organomet. Chem. 1977, 132, C17.

5. (a) Negishi, E.; Van Horn, D. E. J. Am. Chem. Soc. 1977, 99, 3168. (b) Okukado, N.; Van Horn, D. E.; Klima, W. E.; Negishi, E. Tetrahedron Lett. 1978, 1027.

6. For early contributions by other workers on Pd-catalyzed cross-coupling with Grignard reagent, see: (a) Yamamura, M.; Moritani, I.; Murahashi, S.-I. J. Organomet. Chem. 1975, 91, C39. (b) Fauvarque, J. F.; Jutand, A. Bull. Soc. Chim. Fr. 1976, 765. (c) Sekiya, A.; Ishikawa, N. J. Organomet. Chem. 1976, 118, 349.

7. (a) For the first successful Pd-catalyzed cross-coupling with organoboron compounds, see: Negishi, E. In Aspects of Mechanism and Organometallic Chemistry; Brewster, J. H. Ed.; Plenum: New York, 1978; pp 285-317. (b) For a seminal work on Pd-catalyzed allylation of boron enolates, see: Negishi, E.; Matsushita, H.; Chatterjee, S.; John, R. A. J. Org. Chem. 1982, 47, 3188.

8. For the earliest contribution by the Suzuki group on Pd-catalyzed cross-coupling on organoboron compounds, see: (a) Miyaura, N.; Yamada, K.; Suzuki, A. Tetrahedron Lett. 1979, 3437. (b) Miyaura, N.; Suzuki, A. J. Chem. Soc., Chem. Commun. 1979, 866.

9. For the first publication on Pd-catalyzed cross-coupling with organotins, see: Kosugi, M.; Sasazawa, K.; Shimizu, Y.; Migita, T. Chem. Lett. 1977, 301.

10. (a) Jabri, N.; Alexakis, A.; Normant, J. F. Tetrahedron Lett. 1981, 22, 959. (b) Jabri, N.; Alexakis, A.; Normant, J. F. Tetrahedron Lett. 1982, 23, 1589.

11. For a pivotal contribution on high-yielding and selective Hiyama coupling promoted by $\left(\mathrm{Et}_{2} \mathrm{~N}\right)_{3} \mathrm{~S}^{+}\left(\mathrm{Me}_{3} \mathrm{SiF}_{2}\right)^{-}$(TASF), see Hatanaka, Y.; Hiyama, T. J. Org. Chem. 1988, 53, 918.

12. (a) Pérez, I.; Sestelo, J. P.; Sarandeses, L. A. Org. Lett. 1999, 1, 1267. (b) Pérez, I.; Sestelo, J. P.; Sarandeses, L. A. J. Am. Chem. Soc. 2001, 123, 4155.

13. Riguet, E.; Alami, M.; Cahiez, G. Tetrahedron Lett. 1997, 38, 4397.

14. (a) For an earlier review, see: Negishi, E. Acc. Chem. Res. 1982, 15, 340. (b) For a comprehensive review as of 2000, see: Negishi, E.; de Meijere, A., Eds. Handbook of Organopalladium Chemistry for Organic Synthesis, Wiley-Interscience, New York, 2002, 
Part III, pp 215-1119. (c) For a recent review with emphasis on alkene syntheses, see: Negishi, E.; Wang, G.; Rao, H.; Xu, Z. J. Org. Chem. 2010, 75, 3151.

15. (a) Miyaura, N.; Suzuki, A. Chem. Rev. 1995, 95, 2457. (b) Suzuki, A.; Brown, H. C. Organic Syntheses via Boranes, Vol. 3: Suzuki Coupling, Aldrich Chemical Co., Milwaukee, 2003, p 314.

16. Negishi, E.; Xu, S.; Truex, N.; Rao, H.; Tobrman, T.; Mohan, S.; Gao, J.; Maishal, T. manuscript in preparation.

17. (a) Heck, R. F.; Nolley, J. P., Jr. J. Org. Chem. 1972, 37, 2320. (b) Heck, R. F. Org. React. 1982, 27, 345-390. (c) Beletskaya, I. P.; Cheprakov, A. V. In The Mizoroki-Heck Reaction; Oestreich, M., Ed.; John Wiley \& Sons, Ltd.; Chichester, U. K., 2009; Chapter 2, pp 51-132. (d) Jeffery, T. Tetrahedron Lett. 1985, 26, 2667-2670. (e) Farina, V. Adv. Synth. Catal. 2004, 346, 1553. (f) Lemhadri, M.; Battace, A.; Berthiol, F.; Zair, T.; Doucet, H.; Santelli, M. Synthesis, 1142-1152. Note: Three out of $>40$ examples display TONs of 7000,8100 , and 9500, which represent the three highest TONs exceeding 1000 in this study (Ref. 17f).

18. (a) Van Horn, D. E.; Negishi, E. J. Am. Chem. Soc. 1978, 100, 2252. (b) Negishi, E.; Van Horn, D. E.; Yoshida, T. J. Am. Chem. Soc. 1985, 107, 6639. (c) Olah, G. A. Angew. Chem. Int. Ed. 1993, 105, 767. (d) Negishi, E. Chem. Eur. J. 1999, 5, 411.

19. (a) Kondakov, D. Y.; Negishi, E. J. Am. Chem. Soc. 1995, 117, 10771. (b) Kondakov, D. Y.; Negishi, E. J. Am. Chem. Soc. 1996, 118, 1577.

20. Dzhemilev, U. M.; Vostrikova, O. S.; Sultanov, R. M. Izv. Akad. Nauk SSSR, Ser. Khim. 1983, 218.

21. For a review, see: Negishi, E.; Kondakov, D. Y. Chem. Soc. Rev. 1996, 417.

22. Takahashi, T.; Seki, T.; Nitto, Y.; Saburi, M.; Rousset, C. J.; Negishi, E. J. Am. Chem. Soc. 1991, 113, 6266.

23. Negishi, E.; Kondakov, D. Y.; Choueiry, D.; Kasai, K.; Takahashi, T. J. Am. Chem. Soc. 1996, $118,9577$.

24. Ott, K. C.; deBoer, E. J. M.; Grubbs, R. H. Organometallics 1984, 3, 223.

25. For a review of this subject, see: Negishi, E.; Novak, T. In Comprehensive Organometallic Chemistry III; Ojima, I., Ed.; Elsevier: Oxford, 2007; Chap. 10.06, pp 251-297.

26. (a) Morken, J. P.; Didiuk, M. T.; Hoveyda, A. H. J. Am. Chem. Soc. 1993, 115, 6997. (b) Didiuk, M. T.; Johannes, C. W.; Morken, J. P.; Hoveyda, A. H. J. Am. Chem. Soc. 1995, 117, 7097.

27. (a) Bell, L.; Whitby, R. J.; Jones, R. V. H.; Standen, M. C. H. Tetrahedron Lett. 1996, 37, 7139. (b) Yamamura, Y.; Hyakutake, M.; Mori, M. J. Am. Chem. Soc. 1997, 119, 7615.

28. For a study of zirconocene-catalyzed alkene carbomagnesiation with longer alkylmagnesium derivatives, see: Rousset, C. J.; Negishi, E.; Suzuki, N.; Takahashi, T. Tetrahedron Lett. 1992, 33, 1965.

29. (a) Erker, G.; Aulbach, M.; Knickmeier, M.; Wingbermuhle, D.; Krüger, C.; Nolte, M.; Werner, S. J. Am. Chem. Soc. 1993, 115, 4590. (b) Wild, F. R. W. P.; Zsolnai, L.; Huttner, G.; Brintzinger, H. H. J. Organomet. Chem. 1982, 232, 233. (c) Wild, F. R. W. P.; 
Wasiucionek, M.; Huttner, G.; Brintzinger, H. H. J. Organomet. Chem. 1985, 288, 63. (d) Available from Aldrich Chemical Co., Milwaukee, WI.

30. For a recent review, see: Alt, H. G.; Koppl, A. Chem. Rev. 2000, 100, 1205.

31. (a) Wipf, P.; Ribe, S. Org. Lett. 2000, 2, 1713. (b) Ribe, S.; Kondru, R. K.; Beratan, D. N.; Wipf, P. J. Am. Chem. Soc. 2000, 122, 4608.

\section{Original Papers on ZACA Reactions by the Negishi Group}

Note: For the seminal papers on discovery of the ZACA reaction, see Reference 19.

32. Huo, S.; Negishi, E. Org. Lett. 2001, 3, 3253.

33. Huo, S.; Shi, J.; Negishi, E. Angew. Chem. Int. Ed. 2002, 41, 2141.

34. Tan, Z.; Negishi, E. Angew. Chem. Int. Ed. 2004, 43, 2911.

35. Negishi, E.; Tan, Z.; Liang, B.; Novak, T. Proc. Natl. Acad. Sci. USA 2004, 101, 5782.

36. Magnin-Lachaux, M.; Tan, Z.; Liang, B.; Negishi, E. Org. Lett, 2004, 6, 1425.

37. Zeng, X.; Zeng, F.; Negishi, E. Org. Lett, 2004, 6, 3245.

38. Novak, T.; Tan, Z.; Liang, B.; Negishi, E. J. Am. Chem. Soc. 2005, 127, 2838.

39. Liang, B.; Novak, T.; Tan, Z.; Negishi, E. J. Am. Chem. Soc. 2006, 128, 2770.

40. Tan, Z.; Liang, B.; Huo, S.; Shi, J.; Negishi, E. Tetrahedron: Asymmetry 2006, 17, 512.

41. Huang, Z.; Tan, Z.; Novak, T.; Zhu, G.; Negishi, E. Adv. Synth. Catal. 2007, 349, 539.

42. Zhu, G.; Negishi, E. Org. Lett. 2007, 9, 2771.

43. Huang, Z.; Negishi, E. J. Am. Chem. Soc. 2007, 129, 14788.

44. Zhu, G.; Negishi, E. Chem. Eur. J. 2008, 14, 311.

45. Liang, B.; Negishi, E. Org. Lett. 2008, 10, 193.

46. Zhu, G.; Liang, B.; Negishi, E. Org. Lett. 2008, 10, 1099.

47. Xu, Z.; Negishi, E. Org. Lett. 2008, 10, 4311.

48. Pitsinos, E.; Athinaios, N.; Xu, Z.; Wang, G.; Negishi, E. Chem. Commun. 2010, 46, 2200.

\section{Reviews, Book Chapters, Procedures, and Patents on ZACA Reaction by the Negishi Group}

Note: For the earliest review on ZACA reaction, see Reference 21. See also Reference $18 \mathrm{~d}$.

49. Negishi, E. Chapter 4 in Catalytic Asymmetric Synthesis II, Ojima, I., Ed., J. Wiley-VCH, New York, 2000, pp 165-189.

50. Negishi, E. Pure Appl. Chem. 2001, 73, 239.

51. Negishi, E.; Huo, S. Pure Appl. Chem. 2002, 74, 151.

52. Negishi, E.; Huo, S. Chap. 1 in Titanium and Zirconium in Organic Synthesis, Marek, I., Ed., Wiley-VCH, Weinheim, 2002, pp 1-49.

53. Negishi, E.; Tan, Z. Chap. 4 in Topics in Organometallic Chemistry, Takahashi, T., Ed., Springer, 2004, pp 139-176.

54. Negishi, E. J. Chem. Soc., Dalton Trans. 2005, 827. 
55. Negishi, E.; Kondahov, D. Y. Chiral Organoalanes and Their Organic Derivatives via Zirconium-Catalyzed Asymmetric Carboalumination of Terminal Alkenes, US Patent 6, 002, 037, Dec. 14, 1999 (Applied Oct. 14, 1997).

56. Negishi, E.; Huo, S. (-)-Dichlorobis[(1,2,3,3a,7a- $)-1-[(1 S, 2 S, 5 R)-5-$ methyl-2-(1-methylethyl)cyclohexyl-1H-inden-1-yl]zirconium and Its (+)-(1R,2R,5S)-Isomer, In Encyclopedia of Reagents for Organic Synthesis, Paquette, L. A., Ed., Wiley, New York, 2002.

57. Negishi, E.; Wang, G.; Lee, C. T.; Xu, S. manuscript in preparation.

\section{Author's Biography}

\section{Professor Ei-ichi Negishi}

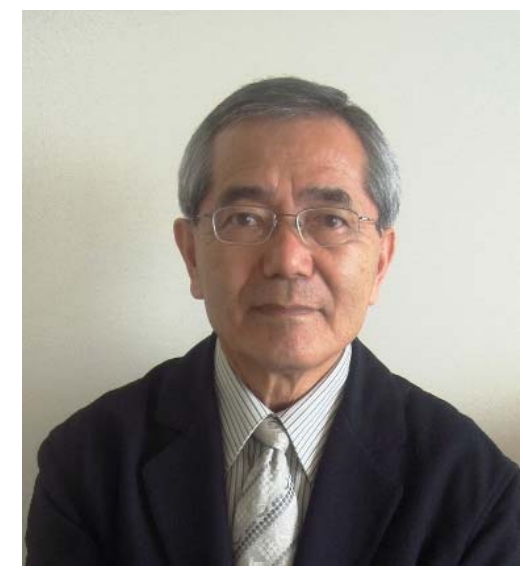

Ei-ichi Negishi, H. C. Brown Distinguished Professor of Chemistry, Purdue University, grew up in Japan and received his Bachelor's degree from the University of Tokyo in 1958. After he obtained his Ph.D. degree from the University of Pennsylvania in 1963, he joined Professor H. C. Brown's Laboratories at Purdue as a Postdoctoral Associate in 1966 and was appointed Assistant to Professor Brown in 1968. Negishi went to Syracuse University as Assistant Professor in 1972 and began his life-long investigations of transition metal-catalyzed organometallic reactions for organic synthesis. Negishi was promoted to Associate Professor at Syracuse University in 1976 and invited back to Purdue University as Full Professor in 1979. In 1999 he was appointed the inaugural H. C. Brown Distinguished Professor of Chemistry. He has received various awards, with the most representative being the 1998 ACS Award in Organometallic Chemistry, the 2010 ACS Award for Creative Work in Synthetic Organic Chemistry, the honor of 2010 Japanese Order of Culture, and the 2010 Nobel Prize in Chemistry. 